\title{
An overview of design, construction, and installation of gravity offshore platforms
}

\author{
Omar Ahmad \\ Civil Engineering Department, Near East University, Nicosia, Via Mersin 10, Turkey
}

ARTICLE INFO

ARTICLE HISTORY:

Received: 27 December 2020

Revised: 29 February 2021

Accepted: 18 June 2021

Published: 28 September 2021

KEYWORDS:

\begin{abstract}
A B S T R A C T
The offshore structures are used worldwide in different ways and for different purposes in a variety of weather conditions and water depths. The main aim of these structures is to explore and extract the gas and oil and they should work safely for approximately 25 years or more against some conditions. These structures play a vital role in developing the economic level of the country and it is essential to be accurate in all of their planning, designing, manufacturing, transporting, and installing processes. There are many types of platforms that differ according to their function and the needed water depth. Gravity platform or ConDeep platform is one of these platforms that is fixed offshore platform, made by concrete. The purpose of this paper is to give an informative overview of the advantages, disadvantages, materials used, design, construction, transportation, and installation of gravity platforms.
\end{abstract}

Offshore, gravity platform, structure, construction, design

\section{INTRODUCTION}

The demand for energy, gas and oil is always increases and this is the main reason for creating and developing offshore structures. The offshore structures are mostly built in areas where there is gas and oil at a certain distance from the shoreline. The aim of these structures is to explore and extract gas and oil and sometimes for electric purposes. The offshore structures are used worldwide in different ways and for different purposes in a variety of weather conditions and water depths. Oil exploration, ship loading and unloading, navigation and bridges support are all uses of the offshore platforms in which oil production is considered as one of the most important uses (Sadeghi, 2007). The offshore structures must function safely for 25 years or more against some conditions. It is essential to be accurate in planning, fabricating, designing, transporting, installing, and selecting the type of offshore platform (Sadeghi, 2008). Offshore structures are very important because of their great influence on the economic development of the countries and they are relying on different conditions like structural and ecological conditions (Sadeghi \& Bichi, 2018). Offshore structures are very significant and considered among the tallest structures all over the world. They should be well operated because of the environmental challenges (Nouban et al., 2017). Offshore structures are so complicated structures that require many aspects in the design and construction processes. In the case of deepwater and harsh environmental conditions, the fixed platforms are used to obtain the stiffness and strength needed for the structures (Sadeghi \& Guvensoy, 2018).

\subsection{Types of offshore platforms}

The offshore platforms can be categorized into three main categories which are fixed platforms, compliant platforms and floating platforms. These main categories can also be further categorized as follows:

\subsubsection{Fixed platforms}

- Jack-up rigs (when drilling),

- Gravity-based structures,

- Jacket platforms. 


\subsubsection{Compliant platforms}

- Tension leg platform,

- Articulated tower,

- Guyed tower.

\subsubsection{Floating platforms}

- Floating production unit,

- Spar,

- Semisubmersible,

- Floating production, storage, and offloading system,

- Floating storage and offloading.

(Chandrasekaran, 2018).

\section{GRAVITY PLATFORMS}

Gravity platforms are fixed offshore platforms which are made of concrete (Fig.1.). ConDeep platforms are the other name of gravity platforms and they are mostly used in the side of Brazilian water and the North Sea (Nouban et al., 2016). Gravity platforms are used in the North Sea because their foundations are large and have long height so no additional fixing and also because the sea bed materials are consolidated in the North Sea (Clauss et al., 1992).

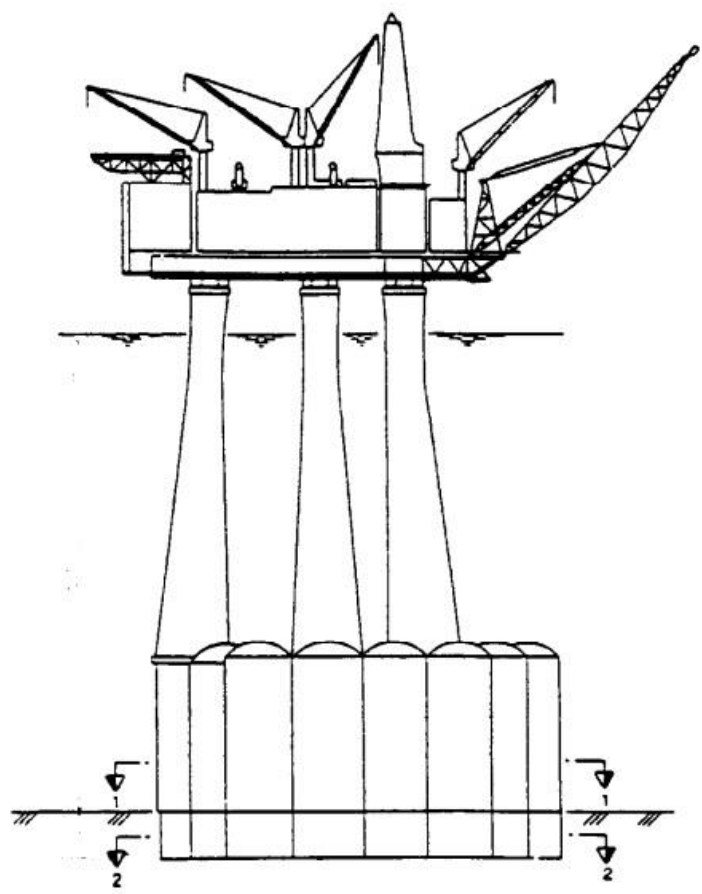

Fig. 1. Gravity platform (Langena et al., 1998)

Table 1. Gravity offshore platforms constructed worldwide (Chandrasekaran, 2018)

\begin{tabular}{|l|c|}
\hline Name of platform & Water depth (m) \\
\hline Troll & 330 \\
\hline Draugen & 280 \\
\hline Heidrun & 280 \\
\hline Slebner & 80 \\
\hline Oseberg & 100 \\
\hline Maureen & 95.6 \\
\hline Ekofisk 1 & 70 \\
\hline Osberg north & 100 \\
\hline Cormorant & 149 \\
\hline Ninian & 136 \\
\hline Dunlin A & 153 \\
\hline Frig TP 1 & 104 \\
\hline Frig CDP1 & 98 \\
\hline Frig MCP01 & 94 \\
\hline Frig TCP2 & 103 \\
\hline Gulfaks a & 133.4 \\
\hline Gulfaks b & 133.4 \\
\hline Gulfaks C & 214 \\
\hline Beryl A & 119 \\
\hline Brent B & 140 \\
\hline Brent C & 145 \\
\hline Brent D & 145 \\
\hline Statfjord A & 145 \\
\hline Statfjord B & 145 \\
\hline Statfjord C & 190 \\
\hline
\end{tabular}

The gravity platform contains 24 cylindrical cells located at the caisson (the lower part). The approximate diameter and height of cells are $24 \mathrm{~m}$ and $77 \mathrm{~m}$ respectively. In order to carry the deck, four of these cells are elongated. Moreover, some of these cells are extended downward and penetrate the seabed to form the skirts (Langena et al., 1998). Table 1 shows the gravity offshore platforms constructed worldwide.

\subsection{Advantages of gravity offshore platforms}

Advantages of gravity offshore platforms are as follows:

- Safe for the people working on it,

- Possibility of towing to the site with the deck,

- Less time in installation and less cost,

- Less maintenance cost because the concrete in water has lesser problems than the steel,

- Crude oil capacity can be adjusted,

- Can support large areas of decks, 
- Healthy monitoring because there is an excess to the seabed from the cell in the foundation.

\subsection{Disadvantages of gravity offshore structures}

Disadvantages of gravity offshore platforms are as follows:

- Inappropriate for the sites with poor soil conditions,

- Construction process takes a long time which leads to delay in production,

- Falling of the natural frequencies during the range of power of the wave spectrum (Chandrasekaran, 2018).

\subsection{Materials}

- The requirements for the materials are as follows:

- Compressive concrete strength $65 \mathrm{Mpa}$,

- Maximum water-cement ratio 0.4,

- Cement material content $360-450 \mathrm{~kg} / \mathrm{m}^{3}$,

- Maximum silica fume content $8 \%$,

- Maximum fly ash content $30 \%$,

- Slump $240 \mathrm{~mm}$,

- Coefficient of chloride diffusion $4 \times 10^{-12} \mathrm{~m}^{2} / \mathrm{s}$,

- Freezing and thawing are resistant to splash zone $2-4 \%$ air entrainment (Widianto et al., 2016).

\subsection{Design considerations}

Gravity offshore platforms are giant structures and according to the different loads that are imposed on them, there are some considerations that should not be overlooked which are:

- The oil storage must be accurately designed and it should be tight with respect to the oil leakage which means that there should be no cracks and only very limited cracks are accepted,

- The internal pressure of the oil must be less than the external pressure of water,

- Temperature stresses caused by hot oil,

- Instability of the walls and columns of the caisson,

- Local earth pressure,

- Fatigue damage at the bases of columns (Otunyo, 2011).

\subsection{Loads considered in the design}

The gravity offshore platforms are exposed to many horizontal and vertical loads that should be taken into consideration in the design process. The loads are as follows.

\subsubsection{Dead loads}

The dead loads are the weights of the structure that include deck, jacket, piping, anodes, boat landing, grating, and all the equipment which are fixed and permanent (AlSharif, 1995).

\subsubsection{Live loads}

The live loads are the loads that that are not permanent on the platform and may change in the different steps of operation. They include the weight of workers working on the platform, impact loads, helicopter loads, and the crane operation (Al-Sharif, 1995).

\subsubsection{Ice and snow loads}

When the structures are located in the Polar Regions or in the side of cold countries the ice and snow loads must be taken into consideration because their high intensity can create a big load on the structure and it may happen suddenly to the structure. An empirical formula can be used in order to calculate the ice force (Kharade \& Kapadiya, 2014).

$$
F_{\text {ice }}=C f A
$$

where:

$C$ : the coefficient of ice force which varies between 0.3 and 0.7 ,

$f$ : the ice crushing strength which varies between 1.5 and $3.5 \mathrm{Mpa}$,

$A$ : the area struck by ice which equals to diameter times the thickness.

\subsubsection{Wind forces}

For the design of the gravity offshore platform, the wind-induced loading which can also be called as drag force should be evaluated. During the estimation of the windinduced loading, some predictions are used for instance neglecting higher-order wind-induced loading and by using turbulent wind spectral formulations. The drag force can be evaluated by applying the following equation (Jang \& JyhShinn, 1999).

$$
F_{D}=1 / 2 \rho C D A U^{2}(t)
$$

where:

$F_{D}$ : the drag force,

$\rho:$ the density of air,

$A$ : the area of the structure,

$U(t)$ : incident wind speed. 


\subsubsection{Wave forces}

Evaluation of the wave slamming and slap forces on the structure is necessary and it can be included in the equation of motion if warranted. The wave forces that are imposed on the columns are the source of tendon responses and should be calculated in order to design (Sadeghi \& Tozan, 2018). In order to analyze and indicate the wave data sensing by satellites, measuring devices and simulation models are used. The simulation models are mostly used in the world because it is simple and can be applied for most of the geographical areas while the two other methods are not widely used because they consume a long time, are expensive and not available for all regions (Sadeghi, 2007). The wave loads that are imposed on the structure create an overturning moment on the structure. In the design, the maximum wave height has to be used and it has a relationship with the significant wave height which is shown below (Kharade \& Kapadiya, 2014).

$$
H_{\max }=1.86 H_{s}
$$

where:

$H_{\text {max }}$ : the maximum wave height,

$H_{s}$ : the significant wave height.

\subsubsection{Earthquake loads}

The offshore structures are exposed sometimes to lateral loads that may exceed their elastic limit. In some regions, the seismic loads are higher than other regions so the regions where the seismic loads are more active should be accurately designed against these loads in order to prevent any failure (Bargie et al., 2011).

\subsubsection{Current loads}

The currents in oceans create a drag loading on the offshore structures and they consist of tidal and wind-driven currents. The tidal currents vary with the change of depth but non-linearly on the contrary of wind-driven currents that vary linearly with the water depth. These currents can be expressed as follows (Kharade \& Kapadiya, 2014).

$$
\begin{aligned}
& V_{T}=V o_{T} y^{1 / 7} / h \\
& V_{W}=V o_{W} y / h
\end{aligned}
$$

where:

$V_{T}$ : the tidal current at any height,

$V_{T}$ : the tidal current at the surface,

$V_{W}$ : the wind-driven current at any height,

$V o_{W}$ : the wind-driven current at the surface,

$y:$ the distance from the seabed,

$h$ : the water depth.

\subsubsection{Fabrication, transportation, load out and installation forces}

The procedures and guidelines for fabrication must be followed and done as recommended to reduce the concentration of stress upon welding and misalignment and to deprive the cracks in the welds. Furthermore, the barge motion and the forces that may occur upon lifting or loadout with not equally slings must be considered in the design to make sure that the structure can resist these forces (AlSharif, 1995).

\subsection{Construction and fabrication}

The supports of the gravity-based structure can be categorized into three generations and each generation can be constructed in a different place. The dry dock is the first place where the construction of supports can occur and it is used in the first generation of gravity-based structures. The dry dock is flooded when the supports are ready to be floated out Fig.2. Floating pontoons is another place where the construction of supports can occur in which the supports are constructed on semisubmersible barge or floating pontoons and it is used in the second generation.

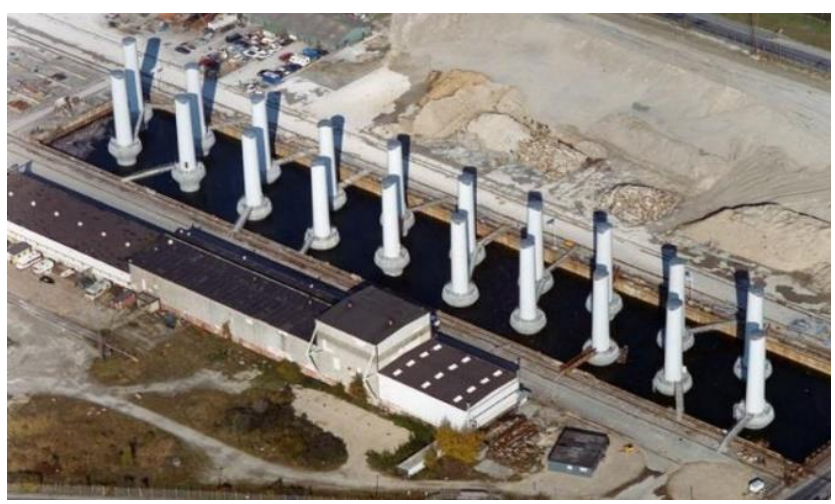

Fig. 2. Construction of supports in dry dock (Ruiz de Temino Alonso, 2013)

The advantages of this method are no need for a large area for construction in the port and there is no need for operation of floating and loading out in which the supports can be directly transported to the final destination Fig.3. Moreover, onshore can be another choice of supports construction in which the supports are constructed in the port and it is used in the third generation. The quayside may have to be reinforced because of the high requirements of the supports Fig.4 (Esteban et al., 2015). 


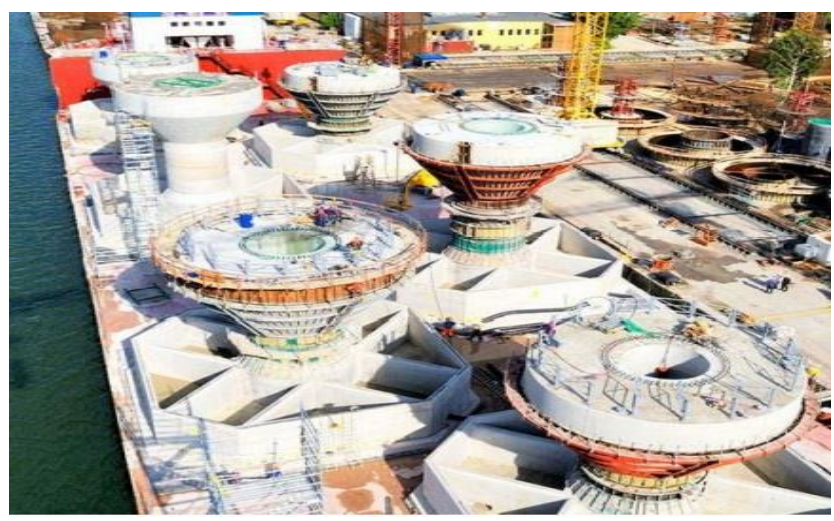

Fig. 3. Construction of supports on semisubmersible barge (Ruiz de Temino Alonso, 2013)

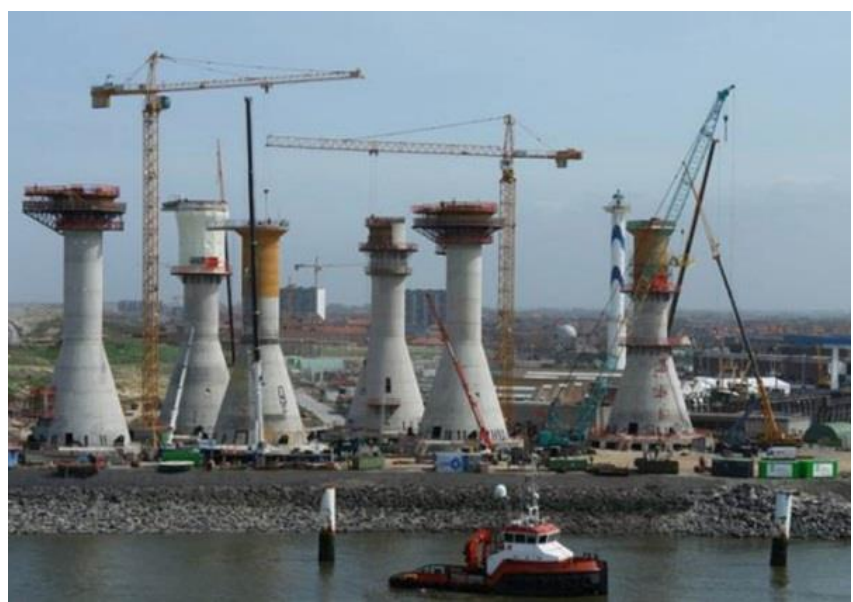

Fig. 4. Construction of supports on the quayside (Ruiz de Temino Alonso, 2013)

\subsection{Transportation}

For the cases of the first generation which are constructed on the dry dock, after building the structure and floating it out, the heavy-lift vessel barge is used for transporting and installing the supports. It should be modified to achieve the member's weights of structure and water depth requirements. Moreover, it should fit the shapes and sizes of supports. For the cases of the second generation which are constructed on the floating pontoon, after finishing the construction of the supports, they can be transported by the barge. In this case, the barge must follow the requirements of the international maritime organization IMO or any International Association of Classification Societies IACS members. For the cases of the third generation which are constructed on the onshore, a floating

pontoon is used for transporting the supports. (Esteban et al., 2015).

\subsection{Installation}

The installation process is positioning and levelling of the offshore platform according to the design drawings and assembling the different components of the structure in order to make it a stable structure (Muyiwa \& Sadeghi, 2007). There are two techniques for installation of the structures which are an individual installation by using the heavy left vessel and installation of several supports by loading them on semisubmersible barges. The first technique is used when the construction occurred on the onshore and dry dock while the second technique is used when the construction occurred on the semisubmersible or floating barge. In all cases, the supports are lowered and installed to the seabed by heavy lift vessel Fig. 5. The advantages of the second technique are transferring the supports by one trip, faster in towing, safer, and easier if any problem occurred due to the weather conditions (Esteban et al., 2015).

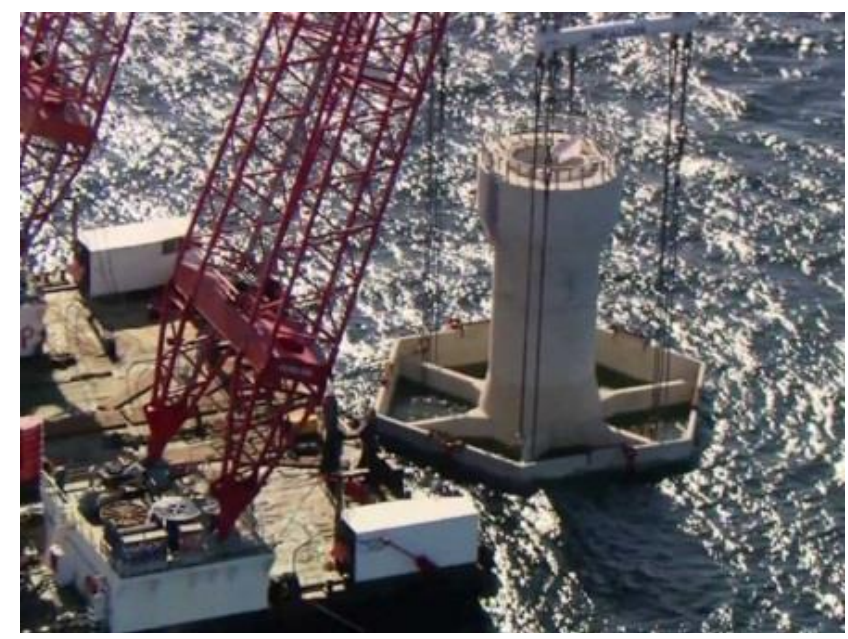

Fig. 5. Installation of the supports (Ruiz de Temino Alonso, 2013)

In some situations, the seabed under the structure may need some preparations so in this case the preparation process should be started before the arrival of foundations. The backhoe on a pontoon prepares the seabed by installing and levelling a layer of gravel. After preparation of the seabed and arrival of foundations to the location, the heavylift vessel lifts the foundations and lowers them to their final destination. Then in order to withstand the applied loads, the foundations are ballasted. The next step is the installation of the quarry stone layer in order to prevent the erosion of the gravel layer (Ruiz de Temino Alonso, 2013). 


\section{CONCLUSION}

In this paper, some information about the advantages, disadvantages, materials used, design, construction, transportation and installation of gravity platforms has been described. Gravity platforms differ from the other offshore structures in the design, construction and installation processes. This type of fixed offshore structure is worldwide used because of its advantages at special water depths.

\section{CONFLICT OF INTEREST STATEMENT}

The author declares that there is no conflict of interest.

\section{REFERENCES}

[1] Al-Sharif, A. A. (1995). Design, fabrication and installation of fixed offshore platforms in the Arabian Gulf. The Fourth Saudi Engineering Conference. Saudi Arabian Oil Company, Dhahran, Saudi Arabia, November 1995, 99-105.

[2] Bargi, K., Hosseini, S.R., Tadayon, M.H., \& Sharifian, H. (2011). Seismic Response of a Typical Fixed JacketType Offshore Platform (SPD1) under Sea Waves. Open Journal of Marine Science. 1(2), 36-42. http://dx.doi.org/10.4236/ojms.2011.12004

[3] Chandrasekaran, S. (2018). Dynamic Analysis and Design of Offshore Structures. Singapore: Springer, Vol.9, 2018, 12-16. https://doi.org/10.1007/978-981-10-6089-2

[4] Clauss, G., Lehmann, E., \& Ostergaard, C. (1992). Offshore structures. Conceptual design and hydromechanics. London: Springer-Verlag, Vol. I, 1992, 64. http://doi.org/10.1007/978-1-4471-3193-9

[5] Esteban, M.D., Couñago, B., López-Gutiérrez, J.S., Negro, V., \& Vellisco, F. (2015). Gravity based support structures for offshore wind turbine generators: Review of the installation process. Ocean Engineering. 110(1), 281-291. https://doi.org/10.1016/j.oceaneng.2015.10.033

[6] Jang, J., \& Jyh-Shinn, G. (1999). Analysis of Maximum Wind Force for Offshore Structure Design. Journal of Marine Science and Technology. 7(1), 43-51.

[7] Kharade, A., \& Kapadiya, S. (2014). Offshore Engineering: An Overview of Types and Loadings on Structures. International Journal of Structural and Civil Engineering Research. 3(2), 16-28.

[8] Langena, I., Skjbtadb, O., \& Haver, S. (1998). Measured and predicted dynamic behaviour of an offshore gravity platform. Applied Ocean Research. 20(1), 15-26. https://doi.org/10.1016/S0141-1187(98)00010-8
[9] Muyiwa, O., \& Sadeghi, K. (2007). Construction planning of an offshore petroleum platform. GAU J. Soc. \& Appl. Sci. 2(4), 82-85.

[10] Nouban, F., French, R., \& Sadeghi, K. (2016). General guidance for planning, design and construction of offshore platforms. Academic research international. 7(5), 37-44.

[11] Nouban, F., Sadeghi, K., \& Abazid, M. (2017). An Overall Guidance and Proposition of a WBS Template for Construction Planning of the Template (Jacket) Platforms. Academic Research International. 8(4), 3756.

[12] Otunyo, A. (2011). Design of Offshore Concrete Gravity Platforms. Nigerian Journal of Technology. 30(1), 34-46.

[13] Ruiz de Temiño Alonso, I., 2013. Gravity Base Foundation for Offshore Wind Farms. Marine Operations and Installation Processes. Master in European Construction Engineering (Final thesis).

[14] Sadeghi, K. (2007). An Overview of Design, Analysis, Construction and, Installation of Offshore Petroleum Platforms Suitable for Cyprus Oil/Gas Fields. GAU J. Soc. \& Appl. Sci. 2(4), 1-16.

[15] Sadeghi, K. (2007). A numerical simulation for predicting sea waves characteristics and downtime for marine and offshore structures installation operations. GAU J. Soc. \& Appl. Sci. 3(5), 1-12.

[16] Sadeghi, K. (2008). Significant guidance for design and construction of marine and offshore structures. GAU J. Soc. \& Appl. Sci. 4(7), 67-92.

[17] Sadeghi, K., \& Bichi, A. (2018). Offshore Tower Platforms: An Overview of Design, Analysis, Construction and Installation. Academic Research International. 9(1), 62-70.

[18] Sadeghi, K., \& Guvensoy, A. (2018). Compliant Tower Platforms: A General Guidance for Analysis, Construction, and Installation. Academic Research International. 8(4), 37-56.

[19] Sadeghi, K. \& Tozan, H. (2018). Tension leg platforms: An overview of planning, design, construction and installation. Academic Research International. 9(2), 55-65.

[20] Widianto., Khalifa, J., Taborda, G., \& Bidne, K. (2016). Concrete Gravity-Based Structure. ACI committee, 38 (6). 